\title{
El hispanismo y la hispanofilia: una perspectiva histórica
}

\section{Hispanism and hispanophilia: a historical perspective}

\author{
Stanley G. PAYNE \\ University of Wisconsin-Madison \\ sgpayne@wisc.edu
}

Fecha de recepción: 03-11-2019

Fecha de aceptación: 03-02-2020

\section{RESUMEN}

Se plantea un análisis de la evolución del hispanismo como especialidad historiográfica, a partir de una definición básica del mismo para conocer las claves de dicha evolución desde el siglo XVIII. Se compara la escuela de hispanistas franceses con la amplitud de temas y perspectivas del hispanismo anglonorteamericano. Se realiza un estudio más detallado de las aportaciones de los hispanistas norteamericanos y se desglosan tanto los tópicos como los contenidos temáticos y diferentes visiones que se han realizado desde los Estados Unidos. Se plantean unas conclusiones con reflexiones que aspiran a ser provechosas para un mejor conocimiento del significado del hispanismo en la actualidad.

Palabras clave: Hispanismo, Historiografía, Hispanismo norteamericano, Historia cultural Period: siglos XIX y XX.

\section{ABSTRACT}

Hispanism is analysed in terms of its basic definition and especially as historical writing, tracing key aspects of its evolution since the 18th century. The work of French Hispanists is compared with that of their Anglo-American counterparts. Contributions by North American Hispanists receive the greatest attention, in relation to major themes, interpretative perspectives and also particular prejudices. The conclusion presents some final observations that offer a critical perspective concerning recent developments and the changes reflected in the $21^{\text {st }}$ century.

Key words: Hispanism, Historiography, North American Hispanism, Cultural history

Period: $19^{\text {th }}$ and $20^{\text {th }}$ centuries.

\section{INTRODUCCIÓN}

Parece que el vocablo "hispanismo", en la acepción empleada para este dossier — "dedicación al estudio de las lenguas, literaturas o cultura [historia] hispánicas"1 o de

1 Real Academia, Diccionario de la Lengua: https://dle.rae.es/?id=KVoY4pX 
España- cristalizó en la década de 1910-1920, si no antes. Establecido por esas fechas², aunque siempre ha coexistido con otras definiciones del término ${ }^{3}$, en la cristalización de su significado, los escritores o aficionados con interés especial en España o su cultura, se llamaban frecuentemente "hispanófilos", y durante algún tiempo no resultó fácil distinguir entre estos y los hispanistas propiamente dichos, aunque hacia la primera parte del siglo $X X$, el último vocablo se reservaba para los estudiosos eruditos y sistemáticos, normalmente —si bien no siempre- profesores. Algunos de los hispanófilos también escribían, a veces mucho, pero en un sentido más popular y puramente divulgador, y en tonos más míticos, románticos o emocionales.

Rafael Altamira se rebeló contra tal terminología precisamente en el año crítico de 1898, tal vez bajo la presión de las circunstancias, al dudar de que los llamados hispanófilos amasen realmente a España únicamente por escribir sobre el país. Al historiador español le parecían muy influidos por imágenes y conceptos de la España romántica o hasta de residuos de la Leyenda Negra ${ }^{4}$ no muy justos. Por ello, Altamira estimaba que el empleo de tal vocablo fue inexacto y abusivo, y sugirió la designación más neutral de "hispanólogos" para los que escribían regularmente sobre España ${ }^{5}$.

¿Cuándo empezó el hispanismo serio y erudito en la historiografía? Las primeras historias generales de España de autores extranjeros de una calidad notable fueron las obras de los franceses Claude Buffier y Jean Baptiste Duchesne, traducidas al castellano en 1734 y 1749, esta última algo más amplia y en dos tomos. Fueron notables porque no había habido ninguna nueva historia general de España desde los tiempos del Padre Mariana, y estimularon, sin duda, una mayor actividad en los eruditos españoles.

\section{EL HISPANISMO FRANCÉS}

Con algunas excepciones destacadas, los franceses llevarían la batuta principal, tanto de la hispanofilia como de un hispanismo más serio, durante bastante tiempo. La época romántica fue un gran periodo de historiografía francesa en general, con expertos de la talla de François Guizot, pero lo que se leía sobre todo fueron los muchos escritos de los hispanófilos, siendo los franceses los principales responsables en el fomento al gran culto de la España romántica, que alcanzó su apogeo en la década de 18406.

Fue un hispanófilo francés, Prosper Mérimée, el que elaboró lo que sería el segundo gran mito simbólico nacional (después del Quijote), con la creación de Carmen (1845),

2 Sigo a Richard L. Kagan en la obra que coordinó sobre Spain in America: The Origins of Hispanism in the United States, Urbana and Chicago: University of Illinois Press, 2002, p. 2.

3 Estas son la lingüística (como un giro de la lengua) o la político-cultural (como referencia a una cultura común o a los intereses comunes de los países de idioma español). Durante un periodo, sobre todo después de 1934, esta se conocía como "la hispanidad". El diplomático mexicano José Robredo Galguera ha descrito muy bien las muchas acepciones distintas de esta doctrina en la historia en La Hispanidad a través de los siglos, México, D. F., Club España A. C., 1954. El estudio principal de la doctrina franquista de la hispanidad en Hispanoamérica es la tesis doctoral inédita de William B. Bristol, Hispanidad in South America, 1936-1948 (University of Pennsylvania, 1951). Para una historia general de tales doctrinas, véase M. Moraña, Ideologies of Hispanism, Nashville, Vanderbilt University Press, 2005.

4 Técnicamente usar este término en 1898 era anacrónico, porque, aunque ya había sido empleado por Emilia Pardo Bazán, no llegaría a ser moneda corriente hasta el libro de Julián Juderías en 1914, pero las actitudes e imágenes a que refiere ya habían existido por mucho tiempo.

5 R. Altamira y Crevea, "Hispanólogos e hispanófilos", en su obra De historia y Arte (Estudios críticos), Madrid, Librería de Victoriano Suárez, 1898, págs. 213-220.

6 Hay una literatura extensa en español, francés e inglés sobre esto, que es relativamente bien conocida, no siendo necesario repetirla aquí. Para una introducción sucinta, véase R. Núñez Florencio, Sol y sangre: La imagen de España en el mundo, Madrid, Espasa Calpe, 2001, págs. 123-93. 
mito que tendría muy larga vida7. Especialmente, destacaba en esta literatura el libro de viajes, que con respecto a España estaría en boga, con varios altibajos, durante muchísimo tiempo, tanto por parte de hispanófilos como de hispanófobos, hasta la llegada del turismo de masas en la década de 1960.

En aquellos mismos años del romanticismo literario, se presentaron también nuevos estudios históricos eruditos, siendo los franceses otra vez los más activos. El más relevante fue el grafómano Eugène Rosseeuw Saint-Hilaire, catedrático de Historia Antigua en la Sorbona, que pasó muchos años elaborando su Histoire d'Espagne, depuis l'invasion des Goths jusqu'au commencement du XIXme siècle, que ya hacia el final de la misma en 1879 abarcaba catorce tomos de tamaño monumental, pero de calidad mejorable, y que tal vez estaba destinada a ser la historia más extensa de España escrita por un estudioso extranjero. De mejor calidad, aunque algo menos extensos, fueron los nueve tomos de la Histoire d'Espagne de Charles Romey (1839-50).

Ellos fueron, sin embargo, figuras individuales sin formación de escuela. El hispanismo francés institucionalizado no tendría lugar hasta la última parte del siglo XIX, con las primeras asignaturas de lengua y literatura creadas como cátedras universitarias, y luego otras designadas a la historia. En Francia, como en Alemania, primó originalmente el enfoque literario en el desarrollo del hispanismo sistemático o "institucional", sobre todo a partir de Alfred Morel-Fatio, un suizo protestante en sus orígenes, que abarcaría desde la década de 1870 hasta su muerte en 1924. La carrera de Morel-Fatio estuvo ligada a la expansión de las universidades — sobre todo en el suroeste de Francia - con el surgimiento de lo que se llamaba el positivismo profesional en la lingüística y en la historia.

Bajo la Tercera República, tuvo lugar un gran crecimiento de la enseñanza del español en varios niveles, coronado con la creación de las dos primeras revistas profesionales, la Revue Hispanique (1894) y el Bulletin Hispanique (1899). En este nuevo hispanismo moderno y académico, la historia fue también importante. Aunque los líderes no fueron historiadores, algunos, como Morel-Fatio, dedicaron una atención especial a la historia, y este tuvo un cierto impacto en España por su crítica del modo dominante de escribir la historia. Morel-Fatio señaló como graves deficiencias la tendencia a la retórica, la ausencia de método crítico en la investigación, a veces con una documentación limitada y con frecuencia una inclinación hacia el sectarismo político.

Otro aspecto importante del primer hispanismo profesional en Francia fue su participación en las relaciones culturales y político-diplomáticas de los dos países. Las iniciativas francesas formaron el precedente principal en la primera parte del siglo veinte, con la creación de entidades culturales de identidad nacional en el extranjero, empezando con la fundación de la École des Hautes Études Hispaniques à Madrid, de la Universidad de Burdeos en 1909, mientras una red de escuelas francesas en España se expandía. Durante la guerra mundial, el gobierno francés empleó a los hispanistas en la lucha propagandística que se libraba para obtener el apoyo español en la contienda.

Como la opinión en la península se escindió entre derecha e izquierda, había también una división en los hispanistas franceses entre republicanos y tradicionalistas con respecto a la cultura española, salvo que los estudiosos galos estaban unidos en su apoyo al interés nacional francés en la guerra. Estos años marcaron la competición política más aguda

7 El mito hasta quedó incorporado en el nacionalismo oficial del régimen de Franco. La primera película creada bajo el régimen fue la versión actualizada y politizada de Carmen, la de Triana (1938), realizada a través de los estudios de la UFA en Berlín, porque no había ninguno adecuado en la zona nacional. En ella, destacaba la gran voz de Imperio Argentina, quien interpretó el papel de Carmen, cantando de un modo magnífico. 
en que cualquier grupo de hispanistas se haya visto jamás envuelto en sus actividades en España. Una vez terminada la guerra, en París se pasó pronto de cualquier interés serio en una alianza o, siquiera, una entente con España en la cuestión de Marruecos, aunque, contradictoriamente, se deseaba explotar a los hispanistas para continuar creando un apoyo español a los intereses de Francia en otros asuntos. Así, las instituciones francesas prosiguieron después de la guerra sosteniendo y, aún, expandiendo el apoyo a las actividades culturales en España, que alcanzaron su cénit en la década de $1920^{8}$.

Todo esto fue sin duda un trabajo relativamente desinteresado de parte de algunos de los hispanistas franceses, pero naturalmente no se puede decir lo mismo del despliegue de las actividades generales francesas en España durante esta época. Sin duda una minoría de franceses alcanzó un entendimiento más amplio y profundo de los españoles y sus asuntos, pero es dudoso que en general las actitudes en Francia respecto al país —una mezcla de romanticismo y de desprecio - cambiaran tanto. Pero a pesar de toda la politización, el hispanismo francés se enriqueció de esta atención y apoyo, y el número de estudios, algunos de mucha calidad, creció considerablemente. Hay que reseñar, por ejemplo, que en 1913 se editó en París la mejor obra, o al menos la mejor informada, sobre la España actual que se había publicado en cualquier idioma hasta la fecha: L'Espagne au XXe siècle (Étude politique et économique) de Angel Marvaud, ofrecía un cuadro amplio de datos sobre la economía, sociedad y vida política española sin precedentes en la literatura. Aunque la actitud personal del autor respecto a España no estaba totalmente exenta de ciertos prejuicios tradicionales, el libro marcó un hito en los estudios sobre el país, y de todos los hispanistas de esa época en cualquier parte del mundo, Marvaud era el mejor informado sobre la España actual.

En la historia, los hispanistas franceses se han orientado principalmente hacia las épocas medieval y moderna ${ }^{9}$, sobre todo esta última. En las décadas centrales y la segunda parte del siglo XX, destacarían figuras clave, como Marcel Bataillon, Fernando Braudel, Jean Sarrailh, Pierre Chaunu, Noel Salomon, Bartolomé Bennassar, Joseph Pérez y otros. Ellos no solo publicaron obras relevantes sobre ciertos temas, sino también ensayos interpretativos distinguidos, como Entender la historia de España (2011) de Joseph Pérez, o la obra singular de Bartolomé Bennassar, L'Homme espagnol: Attitudes et mentalités du XVIe au XIX siècles (1975). De todos ellos, Bennassar, fallecido en 2018, fue el más versátil. Además de sus destacadas obras sobre la época moderna, publicó la única monografía de calidad sobre la juventud de Franco, una biografía completa de este y una historia objetiva de la Guerra Civil, abarcando sus secuelas en Francia.

\section{EL HISPANISMO ANGLONORTEAMERICANO}

El hispanismo británico ha seguido esencialmente la misma secuencia como su contrapartida en Francia, aunque de un modo más lento y menos intenso, y sin haber pasado por la misma expansión en la primera parte del siglo $\mathrm{XX}$ o haber alcanzado, en general, la misma distinción en historia moderna. Se inauguró en la segunda mitad del siglo XVIII en medio de la Ilustración Escocesa, cuando Edimburgo, en proporción a su población, pudiera ser considerada, con poca exageración, la capital intelectual de Europa.

8 El estudio fundamental de estas cuestiones y del desarrollo del hispanismo francés institucional ha sido realizado por A. Niño, Cultura y diplomacia: Los hispanistas franceses y España (1875 a 1931), Madrid, Editorial CSIC, 1988.

9 Durante el último siglo, la excepción principal a esta observación son los logros muy destacables de Guy Hermet en Historia Contemporánea. 
En los siglos XVIII y XIX no hubo un asunto histórico de la Europa moderna que más impresionara a la mentalidad angloamericana que el de la subida, grandeza y declive de España. Con la ascensión del propio imperio británico, existía la sensación de estar posiblemente pasando por las mismas experiencias. El más destacado de los historiadores escoceses fue William Robertson, el primer hispanista moderno que se dedicó al mundo hispánico en su conjunto. Insistía en la importancia de las fuentes primarias e investigaba en el Archivo de Simancas, donde no es imposible que fuera el primer estudioso extranjero profesional.

En 1769 publicó su History of the Reign of the Emperor Charles $V$ en cuatro tomos, y ocho años más tarde su magnum opus, The History of America, en tres tomos. Esta fue tanto la primera historia del hemisferio occidental como la primera del imperio español americano en su conjunto. Durante bastante tiempo fue una de las obras de historia moderna en inglés más leída. Robertson, sería nombrado poco después rector de la Universidad de Edimburgo, cargo que ocupó durante treinta años. En términos proporcionales, se puede decir que fue posiblemente la mejor universidad del mundo —o una de las dos o tres mejores— durante la época más brillante de toda su historia.

También muy leído fue Robert Watson, pastor protestante y profesor de lógica en St. Andrews University. Publicó su History of the Reign of Philip II en dos tomos en 1777, obra que hacia 1812 había alcanzado su séptima edición. Al morir en 1781, dejó sin terminar su próxima historia, cuya última parte fue concluida por un colega, siendo editada en 1783 con el título History of the Reign of Philip III. Casi un siglo más tarde, el destacado filósofo John Stuart Mill reconocería que en su juventud "mi mayor deleite... y durante mucho tiempo" fueron las obras de Watson ${ }^{10}$.

Aunque las referencias a España eran frecuentes en la literatura inglesa ${ }^{11}$, la atención en el mundo académico británico en la primera mitad del siglo XIX era algo menor que la exhibida en esa época por los estudiosos de Nueva Inglaterra. Mientras los escritores franceses fomentaron el culto a la España romántica, la principal aportación inglesa no fue literaria propiamente dicha, sino las clásicas obras didácticas de George Borrow ${ }^{12}$ y Richard Ford ${ }^{13}$, ambas de notable, aunque desigual, calidad y destinadas a perdurar. Estos libros, que comentaban la historia pero no la investigaban, formaron una parte intrínseca de la literatura de la España romántica, aunque de ningún modo exentos de la perspectiva de la Leyenda Negra, combinando aspectos importantes de ambas tendencias. La obra de Ford, a pesar de su parti pris, fue probablemente la mejor aproximación a una descripción antropológica de España que apareció en el siglo XIX.

Durante la primera mitad del siglo XIX, el verdadero hispanismo en idioma inglés surgió en los Estados Unidos. El primer escritor notable norteamericano sobre España fue

10 Se cita en la entrada "Robert Watson" de Wikipedia [https://en.wikipedia.org/wiki/Robert_Watson_ (historian)].

11 Para la recepción de temas españoles en Gran Bretaña durante el siglo XIX, véanse D. Howarth, The Invention of Spain: Cultural Relations between Britain and Spain 1770-1870, Manchester, Manchester University Press, 2007; M. Moreno Alonso, Las "cosas de España" en Inglaterra: un país ante la mirada de otro, Sevilla, Editorial Alfar, 2007, y también B. Cantizano Márquez, Estudio del tópico de Carmen en los viajeros británicos del siglo XIX. Universidad de Granada, 1999.

12 Borrow fue un excéntrico misionero protestante que llegó a España en un momento complicado y difícil de la Primera Guerra Carlista. Su libro principal, The Bible in Spain (1843), es un volumen de experiencias personales y folklorismo. No fue traducido al español hasta casi un siglo después, y de la mano de Manuel Azaña.

13 La edición original del Handbook (1845) de Ford, es sin duda el libro de viajes sobre España más duradero que se ha escrito jamás. 
Washington Irving, que no fue ni historiador ni hispanista, sino un gran hispanófilo, y ello a pesar de que su primer libro fue el Life and Voyages of Christopher Columbus (1828), que dependía, por su base documental, de las investigaciones de Manuel Fernández de Navarrete. Posteriormente, aceptó la recomendación de un amigo para que visitara Granada, y en cuatro años publicó su The Alhambra: Tales and Sketches of the Moors and Spaniards, un libro destinado a rivalizar con el mito de Carmen de Mérimée, para mantener la versión más canónica y duradera de la España romántica. Christopher Columbus había tenido un gran éxito de venta, pero la Alhambra lo superó pronto, llegando a ser el principal bestseller sobre España que jamás haya sido escrito. En el tiempo actual del siglo XXI sigue vendiéndose, porque su romanticismo se ha mantenido irresistible para cada generación de lectores.

La obra consiste en una serie de relatos fantásticos, pero ningún libro ha hecho más para consolidar dos de los mitos modernos más duraderos y difundidos sobre la historia de España; el mito del "paraíso andalusí", y el mito de la "España oriental". El innegable talento literario de Irving para el relato romántico, a nivel popular, fue un factor fundamental en el éxito de sus escritos. Tales mitos, creados y difundidos esencialmente por la literatura y los comentarios periodísticos o libros de viajes, de un modo u otro perdurarían durante mucho tiempo en las obras y comentarios sobre el país en inglés, y solo serian parcialmente superados por la expansión del hispanismo científico y los grandes cambios históricos en la última parte del siglo XX.

Irving escribió sobre un tema español que ha tenido la vida mas larga, pero el primer hispanista norteamericano moderno fue George Ticknor, primer Smith Professor of Modern Languages en Harvard. Su primera estancia de seis meses en Madrid en 1818 impresionó tanto a los líderes de la Real Academia de la Historia que le eligieron primer miembro correspondiente norteamericano a la edad de 27 años, a pesar de no ser exactamente un historiador. Lo que prueba el interés de la RAH por establecer lazos transatlánticos desde los primeros años de Fernando VII ${ }^{14}$.

Ticknor fue un joven erudito de gran energía y capacidad de concentración, y durante años se dedicó a investigar y escribir una historia general de la literatura española, la primera de esta clase hecha jamás en cualquier idioma ${ }^{15}$. Su History of Spanish Literature, se editó en Nuevo York y Londres en 1849 en tres tomos y 1.600 páginas. Fue un gran logro intelectual, sistemático, detallado y muy analítico pero no prolijo, dada la inmensidad del tema. Ticknor había trabajado a lo largo de treinta años en el empeño, y la extensión y profundidad de sus conocimientos sobre la literatura española no tuvo parangón entre los estudiosos extranjeros, creando una estructura taxonómica de análisis e historia literarios sin precedentes. Tuvo mucho éxito, alcanzando cuatro ediciones en veinte años. También alcanzó gran impacto en España cuando la traducción salió en Madrid en cuatro tomos entre 1851 y 1856, acompañada de 314 páginas de notas de Pascual Gayangos, que ampliaron, explicaron o corrigieron aspectos específicos. Posteriormente se harían traducciones en Francia y Alemania.

Aunque su magnum opus apareció una década después de la primera obra importante de William Prescott, Ticknor fue el primero de los grandes hispanistas estadounidenses,

14 La mejor introducción a la vida de Ticknor es el destacable estudio del chileno I. Jaksic, "Ven conmigo a la España lejana": Ios intelectuales norteamericanos ante el mundo hispano, 1820-1880, México, D. F., Fondo de Cultura Económica, 2007, págs. 79-172.

15 Con la excepción parcial de los dos tomos dedicados a la historia de la literatura en España y Portugal en la gran obra de varios tomos del alemán Friedrich Bouterwek entre 1801 y 1819, la mayor parte de los cuales había sido traducida al castellano una década más tarde. 
sensu strictu, y sus propias opiniones marcaron una pauta en la actitud de los estudiosos norteamericanos respecto a España. Para Ticknor, la literatura "antigua" (medieval) fue lo mejor del país por sus orígenes populares y ancestrales y por su "seriedad moral", libres fundamentalmente de cualquier influencia directa extranjera. Introdujo el término "Siglo de Oro" al inglés, pero encontraba la literatura de esa época menos castiza y menos genuina comparativamente.

En el discurso de inauguración de su cátedra en Harvard (1819), expuso una serie de observaciones y juicios que serían fundamentales para los hispanistas americanos. En él insistió en la absoluta singularidad de la historia de España, debida en gran parte a la conquista árabe y al-Ándalus, que la hacía diferente de cualquier otro país europeo o de cualquier otra parte del mundo. Igualmente creía con firmeza en la existencia de un especial "carácter nacional español" —creencia también común entre sus colegas—, caracterizado sobre todo por "el espíritu caballeresco", el sentido del honor y la prioridad de la religión. Insistía igualmente en la influencia "oriental", producto de los musulmanes, expresado en el amor por el lujo y el refinamiento, y en aspectos de las artes. Recalcaba la influencia desastrosa de la Inquisición y las consecuencias de la decadencia del siglo XVII. A partir de entonces, encontró poco de valor o interés en el país, salvo por la vivacidad de sus habitantes.

La historia de Ticknor provocó cierta reacción patriótica en España, estimulando a José Amador de los Ríos a preparar su propia obra monumental, la Historia crítica de la literatura española, que se editó en siete tomos en Madrid entre 1861 y 1865, aunque no pasó del tiempo de los Reyes Católicos ${ }^{16}$. Fue muy diferente en su tono apologético, pero también en su estilo prolijo y retórico, tan diferente de la manera más concisa y analítica de Ticknor.

La perspectiva histórica de los primeros hispanistas norteamericanos insistía en el ámbito moral, que se creía aplicable también de un modo "presentista" a su propio país. Les fascinaba el auge y expansión de España, e, igualmente, la cuestión de la decadencia y el declive, con sus posibles lecciones aplicables a Estados Unidos. Creían discernir las causas de este fracaso en el fanatismo religioso y el autoritarismo monárquico, el militarismo y el imperialismo. La invasión de México en 1845, como consecuencia de la disputa sobre Tejas les alarmó, porque juzgaban esto una deformación fundamental de la vida política norteamericana que podría lanzarla en un proceso de militarización e imperialismo que pudiera acabar con la República misma. En los últimos años de su vida, Ticknor estaba muy deprimido por la Guerra de Secesión y sus consecuencias. Temía que su país acabaría sufriendo el mismo destino de la España histórica.

Aunque la obra de Ticknor se vendió muy bien, el libro de hispanismo serio que alcanzó el mayor éxito fue History of Ferdinand and Isabella the Catholic (1838), de William Hickling Prescott, que fue editado en tres tomos una década antes ${ }^{17}$. La obra reflejaba la fascinación en el mundo anglosajón con la subida y grandeza del imperio español y, a pesar de su extensión y de ser una obra de historia erudita, atrajo a un gran público. A finales de siglo registraba 64 ediciones y otras 33 en Inglaterra, o sea, más de una edición al año. Llegó

16 Esta consecuencia (si se quiere, "provocación") del primer hispanismo americano tuvo cierto paralelismo a mediados del siglo XX, cuando diversos historiadores hispanistas publicamos en 1961 los primeros estudios profesionales, sistemáticos y relativamente objetivos sobre la época de la Guerra Civil de 1936-1939, y destacadamente la obra de Hugh Thomas. El entonces ministro de Cultura y Turismo, Manuel Fraga Iribarne, tomó la decisión de que en España no se podía dejar este asunto en manos de alguien como el periodista oficioso Joaquín Arrarás, primer biógrafo de Franco, y creó un nuevo gabinete de estudios bajo la dirección de Ricardo de la Cierva, lo que lanzó a este como historiador. La primera obra importante de Ricardo de la Cierva fue un estudio extenso y bien documentado titulado Historia de la Guerra Civil española: Antecedentes (Madrid, 1969), pero que no pasó de julio de 1936.

17 Empleó la costumbre normal en inglés de dar nombres italianos a los Reyes Católicos. 
a ser manual de estudio en muchos colegios en una época en la que las humanidades estaban consideradas como algo muy serio.

Esta primera gran obra de Historia de España en Estados Unidos fue también el primer gran estudio histórico en la breve vida cultural del país. El comienzo del hispanismo historiográfico coincidió así con el inicio de la historia seria en Norteamérica. El trabajo de Prescott alcanzó tanto éxito por tres razones: el tema fue muy atractivo al lector norteamericano, Prescott escribía muy bien y de un modo mucho más interesante que un erudito típico, y su modo de tratar la historia fue mucho más amplio que lo normal, una aproximación a lo que se llamaría más tarde l'histoire totale. Prescott presentaba una historia institucional del desarrollo y la unificación de España en la última parte de la Edad Media, pero también trataba las relaciones internacionales y el contexto histórico, mientras daba una atención considerable a la cultura y la literatura, y no ignoraba el desarrollo social y económico. La base documental fue abrumadora, con datos de fuentes primarias de archivos españoles, publicaciones modernas y libros raros del siglo XVI, que llegaron a formar parte de la biblioteca extraordinaria de Prescott. Para su época, esta primera gran obra hispanista norteamericana fue un logro cultural notable, aunque tuvo también sus idiosincrasias.

Prescott nunca fue profesor, sino un "estudioso independiente", como se dice actualmente, de una familia próspera. Lo que hizo que su carrera fuera aún más extraordinaria fue su condición de ser semi-ciego, tras la pérdida de un ojo en un accidente estudiantil y la vista dañada y limitada en el otro. Podía leer solamente con una lupa de gran aumento y nunca viajó a España, valiéndose de colaboradores que le buscaban los documentos y le hacían las copias a mano de los papeles clave. No cabe duda de que fue un verdadero héroe de la cultura. Posteriormente, investigó la conquista de América con la gran History of the Conquest of México, with the Life of the Conqueror Hernando Cortés (1843), en tres tomos, y History of the Conquest of Perú (1847), en dos volúmenes. Y luego volvió a la Historia de España misma con su última gran obra, History of the Reign of Philip II, King of Spain (1853), en dos tomos.

Su interpretación de la Historia de España no difería mucho de la de Ticknor, reflejando la perspectiva común de los primeros hispanistas anglosajones. La admiración por los grandes logros históricos de los españoles coexistía con las actitudes críticas comunes. Richard Kagan, ha afirmado en lo que llama el "paradigma de Prescott" —común en toda esa época-, la idea de que España y Estados Unidos constituyeron antítesis fundamentales y naturales; España siendo monárquica, católica, intolerante y antiprogresista, mientras que Estados Unidos representaba el republicanismo, el protestantismo, la tolerancia y el progreso moderno ${ }^{18}$. Se creía en el "carácter nacional español", aunque existía también la tendencia a creer en el "mito de al-Ándalus", acuñado originalmente en el siglo XVIII, pero a diferencia de los fanáticos de este último mito, se daba bastante énfasis también a la Reconquista, cuya interpretación quedaba algo ambigua. Aunque los primeros hispanistas de la élite de Boston publicaron las primeras grandes obras de historia y estudios literarios eruditos en la vida de la joven República, no formaron una escuela. Después de estas primeras figuras, no hubo gran interés en la investigación sobre España, ni siquiera en cuanto a la lengua y literatura españolas. El francés dominaba en las escuelas y universidades norteamericanas, y "en 1885 había solamente unas diez cátedras de lengua y literatura españolas en todo el país"19.

18 R. L. Kagan, "Prescott's Paradigm: American Historical Writing and the Decline of Spain", American Historical Review 101 (abril 1996), págs. 423-446.

19 R. L. Kagan, The Spanish Craze. America's Fascination with the Hispanic World, 1779-1939, Lincoln, 
Durante las dos últimas décadas del siglo, Yale University llevó la batuta en tratar de cambiar la situación, nombrando en 1879 un segundo catedrático de español, William I. Knapp, quien llegó a ser el más distinguido de los estudiosos en este campo en el país. De un modo análogo, en 1895 la misma universidad nombró al primer catedrático de Historia de España en la persona de Edward Gaylord Bourne, especialista en la historia tanto de España como de Hispanoamérica, quien tuvo una carrera breve pero notable ${ }^{20}$.

Pese a que el ambiente cultural de la "España romántica" disminuyó después de mediados del siglo, sus efectos pervivieron. La última parte del siglo fue una época de internacionalización y de cosmopolitismo entre las capas educadas con el crecimiento de libros de viaje y otras materias tratando de España, a pesar de las tensiones crecientes entre los dos países sobre la cuestión de Cuba. La guerra de 1898 provocó una ola de propaganda antiespañola, reanimando los tópicos de la Leyenda Negra, pero la vida de esta campaña fue breve. Durante el siglo XIX, casi el único trabajo objetivo y fundamentado sobre la España contemporánea en Estados Unidos, fueron las publicaciones del abogado de Baltimore Severn T. Wallis, quien en una serie de ensayos, y luego en su libro de viaje, Glimpses of Spain (1849), y en su estudio Spain: Her Institutions, Politics and Public Men (1853), presentó un análisis diferente, original y acertado, desde la perspectiva de lo que un siglo más tarde se llamaría la "modernización comparada".

Wallis rechazó de plano el concepto y la imagen de la "España romántica", afirmando categóricamente que los escritores extranjeros habían inventado un país que nunca existió. Trató de explicar ciertas realidades de la historia española y de su sociedad y cultura. Señaló las consecuencias de la destrucción impuesta por la invasión napoleónica y, luego, por las luchas civiles, unos trastornos serios pero no duraderos. Llamó la atención sobre las mejoras relativamente rápidas de mediados del siglo, y de los índices de crecimiento económico y reformas nada desdeñables. Como analista del país, no tuvo igual en esa época.

La intensificación leyendanegrista del discurso estadounidense en 1898, se desvaneció pronto con la paz, y los primeros años del siglo XX revelaron una etapa nueva de hispanofilia que no tenía precedentes. Esta hispanofilia norteamericana de las tres primeras décadas del siglo no es fácilmente explicable, pero tenía dimensiones múltiples; como una expresión más seria y sofisticada del mito de la "España romántica", combinada con otras posibilidades del nuevo siglo. No tenía gran inclinación al estudio académico en sí, pero resultó absolutamente decisiva para la enseñanza del español en el país. En esa época, el español asumió por vez primera la posición dominante que ha mantenido hasta nuestra época. Dominio que no tiene peligro de perder en el siglo XXI. Esto quiere decir que los logros principales del hispanismo académico en la primera parte del siglo $\mathrm{XX}$ tuvieron lugar en los campos de la filología y la literatura.

A la vez, emergió una atención publicista mucho más positiva a las iniciativas históricas de España en América, y un interés creciente en la cultura y en la Historia de Hispanoamérica (que en la segunda mitad del siglo veinte sería muchísimo más extensa que la dedicada a España misma). El publicista principal fue Charles F. Lummis, quien nunca visitó España, pero que pasó mucho tiempo en las regiones hispanas del sudoeste estadounidense. Su libro The Spanish Pioneers (1893), cabe dentro del género de lo romántico, presentando una perspectiva totalmente positiva sobre los conquistadores y misioneros, y las numerosas publicaciones de Lummis alcanzaron un público relativamente grande.

University of Nebraska Press, 2019, pág. 183.

20 Como anota Kagan, un alumno de Bourne, Hiram Bingham III, ha sido reconocido por el "descubrimiento" de Machu Picchu en 1911. 
El hispanófilo más decisivo fue el gran coleccionista Archer M. Huntington, heredero multimillonario de una de las grandes fortunas de Estados Unidos, que desde su primera juventud cultivó una fascinación profunda por la historia y la cultura de un país imaginado que solamente visitó por vez primera en 1892, cuando tenía 22 años. Probablemente nunca ha habido otro hispanófilo con tanta dedicación como Huntington. Siendo rico y sin responsabilidades profesionales, podía dedicarse completamente a su pasión. Llegó a tener una vasta colección de obras de arte de todos los géneros, libros y otros elementos, adquiridos en gran parte en galerías especialistas de Francia, porque decía que no quería reducir más la gran herencia española, ya saqueada y expoliada por invasores y coleccionistas extranjeros.

Compró un terreno extenso en el noroeste de Manhattan, y en 1908 abrió su gran museo y biblioteca, The Hispanic Society of América, con grandes salas y galerías para las obras de arte y de arqueología y más de 50.000 libros. Como mecenas y coleccionista, Huntington ha tenido muy pocos equivalentes. Alcanzó una importancia especial en las primeras décadas del siglo $\mathrm{XX}$, fomentando exhibiciones clave que llamaron mucha atención sobre la cultura y la Historia de España ${ }^{21}$, y subvencionó también a otras entidades importantes. En la actualidad, la Hispanic Society sigue abierta en Nueva York.

Duranteestaépocadoradadela hispanofilia norteamericana, los museosy coleccionistas estadounidenses compraron muchísimas obras de arte español, principalmente pinturas, en los últimos años del siglo XIX y el primer cuarto del XX. Y a pesar de la inquina anti-española de sus periódicos en 1898, William Randolph Hearst y otros trasladaron secciones enteras de castillos, monasterios e iglesias a Estados Unidos, a lo que la legislación española ha puesto fin ante tal pérdida de su patrimonio nacional.

En esta primera parte del siglo XX, un aspecto especial fue la popularidad de un nuevo estilo de arquitectura, definido de formas variadas como "Spanish style", "Spanish revival" o "colonial style", o hasta "Mission and Moorish style", en casas particulares, hoteles, teatros y edificios públicos. No era realmente un estilo español, sino una mezcla o síntesis original de elementos de un estilo español (incluido el andalusí y el morisco), y también mexicano (o del suroeste de Estados Unidos) y norteamericano. Se ha empleado especialmente en California y en otras partes del suroeste, y en Florida. En sus años de apogeo —la década de los veinte-, se presentó en la forma de mass-marketing para casas baratas construidas según un modelo central. También se pudo de modo dar nombres españoles ("Alhambra", "Granada", "Aragon", etc.) a teatros y otros centros de recreo. Del mismo modo, se construyeron unas 20 réplicas de la Giralda en varias formas en grandes edificios en las ciudades principales 22 .

La historiografía norteamericana, en cambio, siguió prestando poca atención a España. Durante la "época hispanófila", hubo solamente dos historiadores notables. El primero, Henry Charles Lea, no fue académico, sino un estudioso independiente que había dedicado su vida a la erudición y se especializaba en la historia de la Inquisición. Después de una obra general, History of the Inquisition of the Middle Ages (1887-1888), en dos tomos, pasó a una historia de la expulsión de los moriscos. Poco antes de su muerte se dedicó a la Inquisición española, publicando su magnum opus en 1906-1907, A History of the Inquisition of Spain, en cuatro tomos, falleciendo al año siguiente. El modo de trabajar de Lea no consistió en la narrativa sino en el análisis temático, con atención a los aspectos y categorías individuales, sin que importara el año o época. Sus trabajos llamaron pronto la atención en España,

21 Hay varios estudios, pero la obra más extensa es P. Fernández Lorenzo, Archer M. Huntington. El fundador de la Hispanic Society of America en España, Madrid, Editorial Marcial Pons, 2018.

22 La mejor guía en esta materia es la obra antes citada de Kagan, The Spanish Craze. 
sobre todo de los apologetas católicos, que lanzaron grandes críticas, pero nada menos que Menéndez Pelayo reconoció lo admirable y objetiva que era su investigación. De las muchas obras de los hispanistas en inglés, hay que reconocer que la Inquisition of Spain nunca ha tenido parangón por su absoluta originalidad en el estudio de un gran tema, así como por el rigor y objetividad de su investigación. Por contraste, casi el único historiador de temas españoles de esta época en el Reino Unido fue Martin Hume, esencialmente un divulgador.

Otro notable historiador norteamericano sobre España de la primera parte del siglo fue Roger Bigelow Merriman, profesor en Harvard. Su obra, The Rise of the Spanish Empire in the Old World and the New (1918-1934), en cuatro tomos, coronó el primer siglo del hispanismo estadounidense. Esta obra no fue tan original ni tampoco tan leída como la de Prescott, pero constituyó una síntesis puesta al día de la historiografía sobre el tema, con tomos dedicados respectivamente a la Edad Media, los Reyes Católicos y los dos monarcas del siglo XVI.

Aparte de estas dos notables figuras, el hispanismo norteamericano de la primera mitad del siglo $X X$ se encontraba esencialmente entre los filólogos y estudiosos de la literatura durante una época de muy rápida expansión de la enseñanza del idioma español, ahora constituidos en departamentos de lengua y literatura española (y luego "española y portuguesa"). Dichos departamentos llegaron a tener verdadera importancia, atrayendo por vez primera a intelectuales españoles de primera línea, quienes desarrollaron su carrera en una universidad norteamericana. El primer estudio notable de síntesis de toda esta obra fue el de Miguel Romera-Navarro, El hispanismo en Norte América, publicado en Madrid en 1917.

La hispanofilia de los escritores en Estados Unidos siguió siendo notable con los trabajos románticos de Havelock Ellis, The Soul of Spain (1908) (el libro más notable en inglés, que incluía la literatura sobre el "alma de España" de la generación noventayochista), y el Virgin Spain: Scenes from the Spiritual Drama of a Great People de Waldo Frank (1926). Los más destacados novelistas del país en el segundo cuarto del siglo fueron John Dos Passos y Ernest Hemingway, ambos hispanófilos sobresalientes. Habían sido también muy buenos amigos, aunque luego se distanciaron por la experiencia de la Guerra Civil. Dos Passos, muy progresista, quedó, sin embargo, horrorizado por la "desaparición" en el lado republicano de su amigo el profesor José Robles ${ }^{23}$, mientras Hemingway, más apolítico inicialmente, pasó por una fase de ser propagandista ultra-republicano y por un tiempo apologeta de los comunistas, hasta alcanzar un poco más de equilibro en su famosa novela de la Guerra Civil, Por quién doblan las campanas (aunque después continuó un cierto contacto clandestino con los sovieticos ${ }^{24}$ ). La experiencia de la guerra y del primer franquismo suscitó la última gran oleada de romanticismo en inglés sobre España, para presentar a los republicanos normalmente investidos con los estereotipos más positivos de la España romántica, mientras que la España nacional franquista recibía todos los epítetos clásicos de la Leyenda Negra.

En la segunda mitad del siglo se entró en la época actual del auge del hispanismo historiográfico, producido sobre todo por la gran expansión de las universidades. Esto estimuló el crecimiento de todas las ramas de estudios sobre España, con los principales hispanistas, como siempre, en Francia, Estados Unidos y Gran Bretaña. Por razones coyunturales -

23 El asesinato de Robles ha sido estudiado de un modo preciso y objetivo por I. Martínez de Pisón, Enterrar a los muertos, Barcelona, Editorial Seix Barral, 2005.

24 Durante cinco años la inteligencia soviética le tuvo fichado en su categoría de "fuentes". Véase N. Reynolds, Writer, Sailor, Soldier, Spy: Ernest Hemingway's Secret Adventures, 1935-1961, Nueva York, Editorial William Morrow, 2017. 
sobre todo por la censura franquista- tuvieron, probablemente, su mayor impacto en el campo de la Historia Contemporánea. El primer año notable fue 1961, con la publicación de la versión original de The Spanish Civil War, obra del joven autodidacta británico Hugh Thomas, acompañada por otros dos trabajos más monográficos en inglés. Con estos y otros estudios en la década posterior, los hispanistas conseguimos abrir el campo de la historia reciente del país, mientras que más tarde, con el fin de la censura, llegaría a ser el campo más activo de historia en España, con una concentración de nuevos historiadores españoles, de modo que la contribución de los hispanistas ya no representaba una alternativa. De hecho, desde el fin del siglo XX, los norteamericanos se dedican principalmente a las épocas moderna y medieval, "normalizando" así la historiografía hispanista.

Al comienzo de la década de 1970, la expansión del número de hispanistas en historia en Estados Unidos era tanta que pudo crear su propia organización profesional, originalmente Ilamada Society for Spanish and Portuguese Historical Studies ${ }^{25}$. En su momento máximo contó con más de doscientos estudiosos, aunque no todos norteamericanos y no todos dedicados principal o exclusivamente a la Historia de España. Sociedades semejantes se formaron en Gran Bretaña (con la participación de estudiosos de las ciencias sociales), en la Unión Soviética y, más tarde, en Italia. Alrededor de 1980, un puñado de medievalistas norteamericanos dedicados al tema de España organizaron su propia Academy of Historians of Medieval Spain, que pronto alcanzó un crecimiento exponencial, aunque la gran mayoría de sus numerosos afiliados no se dedican principalmente a la historia medieval española.

La expansión del interés sobre España no se ha limitado al mundo occidental, sino que ha penetrado en Asia, y no meramente en un país grande como China. Desde el inicio del siglo XXI se han venido organizando de vez en cuando pequeños congresos de historiadores hispanistas en un país tan exótico como Corea del Sur. Con el declive de las humanidades en el siglo nuevo, el número de historiadores hispanistas inevitablemente ha descendido, pero se han mantenido la mayor parte de las sociedades nuevas.

Es importante señalar también la contribución notable de historiadores extranjeros a dos campos exóticos más asociados con la historia de España, los estudios sobre los judíos españoles y su cultura, y la gran expansión de la historiografía sobre al-Ándalus y los mudéjares/moriscos. La historia de los judíos españoles ha llegado a ser una gran empresa multinacional, con las mayores contribuciones de investigadores españoles, pero con aportaciones de especialistas de muchísimos países. Igualmente, al-Ándalus ha llegado a ser uno de los países islámicos más ampliamente investigados. Otra vez su investigación es la obra de las últimas generaciones de estudiosos españoles, pero con importantes contribuciones de los historiadores extranjeros en los últimos dos siglos. La obra reciente del estadounidense Brian Catlos, Kingdoms of Faith: A New History of Islamic Spain (2018), es probablemente la mejor historia de al-Ándalus en un solo tomo que se haya hecho. Su perspectiva no es exactamente la del "mito del paraíso andalusí" fomentado desde el siglo XVIII, sino de la de una cultura única peninsular, ni una parte de la civilización occidental ni meramente del mundo islámico exterior-una perspectiva en algunos aspectos convincente, pero en otros harto discutible.

\section{CONCLUSIONES}

La contribución básica del hispanismo es doble. A veces ha llevado a cabo investigaciones originales sin precedentes, aunque hoy en día sería muy difícil igualar o superar el trabajo de los historiadores españoles, al menos en la gran mayoría de asuntos o subcampos individuales. La otra aportación es una dimensión mayor de la historia

25 Posteriormente se denominó Association for Spanish and Portuguese Historical Studies. 
comparada, una cierta perspectiva crítica, a veces más original, en ocasiones presentando importantes obras de síntesis por un solo historiador, una dimensión en que la historiografía española ha sido a veces débil.

Una pregunta fundamental es si los hispanistas han logrado una mayor "objetividad" que los españoles mismos. Eso depende y es relativo. La historia es a la vez una ciencia y un arte, siempre sujeta a ciertas limitaciones del historiador. Durante bastante tiempo han tenido prevalencia en los hispanistas —y aún más en los escritores hispanófilos— varios aspectos de los tópicos de la España romántica o de la Leyenda Negra. De un modo u otro, esto era muy frecuente, casi dominante, como hemos señalado, entre los primeros hispanistas serios de los siglos XVIII y XIX, y de ningún modo estuvo totalmente ausente entre los hispanistas profesionales del siglo $X X$.

Hace años el medievalista William Phillips Jr., señaló la pervivencia de algunos de los estereotipos clásicos en varios de los hispanistas más leídos de la segunda mitad del siglo pasado. The Spanish Labyrinth (1944), del británico Gerald Brenan, sirvió como una especie de guía e introducción para muchos de nosotros a mediados del siglo XX, pero Brenan insistía en los rasgos orientales e islámicos de los españoles, concluyendo que "los estratos más profundos del pensamiento y el sentimiento español son orientales", y que la historia del país había privado a los españoles de la capacidad para gobernarse a sí mismos. Al final se ha ido rectificando, pero hubo de transcurrir años tras el éxito de la Transición. La siguiente obra de historia muy leída fue The Spanish Civil War, de Hugh Thomas, más comedido y equilibrado, aunque insistía en el dominio del sectarismo, el exclusivismo y la violencia en España, en la cual habían faltado "tradiciones comunes a toda España", si no "eran de disputas violentas".

La introducción sobre España que tal vez tuvo el mayor número de ediciones en Estados Unidos durante la segunda mitad del siglo XX fue la del profesor de literatura John Crow, Spain: The Root and the Flower, que batió todos los récords en romanticismo y en estereotipos negativos, con una cuasi sistemática "deprecación de características importantes de España y de los españoles a lo largo de su historia". Según Crow, los españoles son de una "raza afrosemita", medio mora y medio judía, de gran energía pero sin capacidad para cualquier empresa colectiva. Y sobre la época contemporánea afirmaba que, "era como estar de pie en medio de un cementerio y alardear de las hazañas de los muertos, como si estos alardes pudieran hacer que los muertos se levantasen de nuevo y volviesen a la vida"26. Leyendo un libro de esta clase, no está tan claro que la Leyenda Negra haya muerto.

El hispanismo nunca podrá recuperar la importancia relativa que ha tenido a veces en el pasado, como, por ejemplo, en la historia contemporánea durante la década de 1960. La historiografía española del siglo XXI es una empresa grande y diversa, una actividad multinacional con aportaciones de investigadores de muchos países distintos, aunque principalmente de España. Los estudiosos extranjeros han contribuido en todas las épocas, pero actualmente su aportación principal no es tanto la de ofrecer nuevas investigaciones originales -aunque se producen muchas-, como la de presentar una cierta perspectiva diferente, crítica pero relativamente desinteresada y objetiva sobre temas importantes. El hispanismo ha enriquecido la historiografía española y en el siglo XXI refleja una diversidad notable, pero también ha sufrido en muchos casos de sus propias limitaciones y de las diferentes debilidades de muchos historiadores españoles, a veces acusadas.

26 W. Phillips Jr., "La otra cara de la moneda: la imagen de España en los Estados Unidos", en José Manuel de Bernardo Ares, ed., Aportaciones, problemas y perspectivas sobre historia, arte y literatura españolas (siglos XVI-XVIII), Córdoba, Obra Social y Cultural Cajasur, 2001, pp. 161-176. 


\section{BIBLIOGRAFÍA}

Altamira y Crevea, R., "Hispanólogos e hispanófilos", en De historia y Arte (Estudios críticos), Madrid, Librería de Victoriano Suárez, 1898

Bernardo Ares, J. M. (ed.), El hispanismo anglonorteamericano. Aportaciones, problemas y perspectivas sobre historia, arte y literatura españolas (siglos XVI-XVIII), Córdoba, Obra Social y Cultural Cajasur, 2001.

Cantizano Márquez, B., Estudio del tópico de Carmen en los viajeros británicos del siglo XIX. Universidad de Granada, 1999.

Fernández Lorenzo, P., Archer M. Huntington. El fundador de la Hispanic Society of America en España, Madrid, Editorial Marcial Pons, 2018

Howarth, D., The Invention of Spain: Cultural Relations between Britain and Spain 17701870, Manchester, Manchester University Press, 2007

Jaksic, I., "Ven conmigo a la España lejana": Ios intelectuales norteamericanos ante el mundo hispano, 1820-1880, México, D. F., Fondo de Cultura Económica, 2007.

Kagan, R. L., "Prescott's Paradigm: American Historical Writing and the Decline of Spain", American Historical Review 101 (abril 1996), pp. 423-446.

- The Spanish Craze. America's Fascination with the Hispanic World, 1779-1939, Lincoln, University of Nebraska Press, 2019.

Kagan, R. L. (ed.), The Origins of Hispanism in the United States, Urbana and Chicago, University of Illinois Press, 2002.

Martínez de Pisón, I., Enterrar a los muertos, Barcelona, Editorial Seix Barral, 2005.

Moraña, M., Ideologies of Hispanism, Nashville, Vanderbilt University Press, 2005.

Moreno Alonso, M., Las "cosas de España" en Inglaterra: un país ante la mirada de otro, Sevilla, Editorial Alfar, 2007.

Niño, A., Cultura y diplomacia: Los hispanistas franceses y España (1875 a 1931), Madrid, Editorial CSIC, 1988.

Núñez Florencio, R., Sol y sangre: La imagen de España en el mundo, Madrid, Espasa Calpe, 2001.

Reynolds, N., Writer, Sailor, Soldier, Spy: Ernest Hemingway's Secret Adventures, 19351961, Nueva York, Editorial William Morrow, 2017.

Robredo Galguera, J., La Hispanidad a través de los siglos, México, D. F., Club España A. C., 1954.

Romera-Navarro, M., El hispanismo en Norte América: exposición y crítica de su aspecto literario, Madrid, Editorial Renacimiento, 1917 